\title{
SEXUAL DIMORPHISM IN SPLENIAL MORPHOLOGY: A CADAVERIC
} STUDY

\section{Apurba Patra ${ }^{1}$, Arun Sharma ${ }^{* 2}$, Vishal Malhotra ${ }^{3}$.}

${ }^{1}$ Assistant Professor Department Of Anatomy, Dr. Radhakrishnan Government Medical College, Hamirpur, India.

*2 Demonstrator Department Of Anatomy, Government Medical College, Sec 32, Chandigarh, India.

${ }^{3}$ Senior Resident Department Of Spm And Biostatistics, Government Medical College, Patiala India.

\section{ABSTRACT}

Introduction: There is no uniformity in published works regarding the presence of sexual dimorphism in the morphology of the Corpus Callosum (CC), specifically splenium.

Objective: The present study was conducted on formalin fixed preserved brains to get comprehensive data regarding gender related differences of CC.

Materials and Methods: 50 formalin fixed human brains without apparent neuropathology were cut in the midsagittal plane. The various morphometric features of CC were measured and recorded on these midsagittal sections.

The diameters measured were: (i) length of $C C(A B)$, (ii) Width of body of CC at mid point (WBM), (iii) Maximum width of genu (AE), (iv) Maximum width of splenium (BD).

Results: Mean values of two parameters ( $A B$ and $A E$ ) were greater in male than in female. However, 2 parameters $(W M B$ and $B D)$ had greater value in female than male. Only two parameters ( $A B$ and $B D)$ showed statistically significant ( $p$ value $<0.05$ ) gender differences.

Conclusion: significant sexual dimorphism was observed in the longitudinal length of the CC, including morphology of the splenium. However, these gender related differences are more likely due to individual differences regardless of sex.

KEY WORDS: Cerebral Hemisphere, Morphology, Sexual Dimorphism, Splenium.

Address for Correspondence: Dr. Arun Sharma, Demonstrator Department Of Anatomy, Government Medical College, Sec 32, Chandigarh, India. Phone No: +91-7973126936

E-Mail: arun.gmc@gmail.com

Access this Article online

Quick Response code

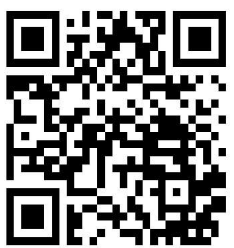

DOI: $10.16965 /$ ijar.2018.423

Journal Information

International Journal of Anatomy and Research

ICV for 2016 ISSN (E) 2321-4287 | ISSN (P) 2321-8967

https://www.ijmhr.org/ijar.htm

DOI-Prefix: https://dx.doi.org/10.16965/ijar

Article Information

Received: 11 Nov 2018

Peer Review: 12 Nov 2018

Revised: None
Accepted: 03 Jan 2019

Published (O): 05 Apr 2019

Published (P): 05 Apr 2019

\section{INTRODUCTION}

The CC is the main fiber tract located in the floor of the longitudinal fissure of the mammalian brain connecting the two cerebral hemispheres [1]. It consists of four anatomical parts. Its anterior end is called the genu or "knee", the central part is the trunk, and the posterior bulbus part forms the splenium. The fourth part is the rostrum, which is the prolongation from the genu to the upper end of lamina terminalis [24]. The CC is undoubtedly the most important 
commissure to connect the two hemispheres due to the wealth of its neural connections. Much of the inter-hemispheric communication in the brain is conducted across the CC [5]. In humans, disputed claims have been made about the gender difference in the morphometry of the CC. Sexual dimorphism in CC might be due to greater bi hemispherical representation of cognitive functions in females. This might not simply be due to sex related differences in brain size and may reflect difference in connectivity necessitated by differences in brain size [6]. On the other hand, there are many reports where no sex related differences in the size and various other measurements of CC have been reported $[5,7,8]$. Most of the research on $\mathrm{CC}$ has been performed on Caucasian brains while very few on Asian population [9]. There are very few studies of CC in the Indian population $[10,11]$. Moreover greater numbers of studies are carried out on MRI scans.

The present study was conducted using formalin fixed preserved brains to get comprehensive data regarding gender related differences of CC in normal adult population in northern region of India.

\section{MATERIALS AND METHODS}

50 mid-sagittal sections ( 38 male and 12 female) from formalin fixed brain specimens were used in this study. Subjects were aged between 45 to 65 years with mean value of age was $55.84 \pm 7.74$ years. Cadavers with any history of intracranial lesions, head injury, recorded brain pathology and visible brain abnormalities were excluded from the study. For this purpose, the whole brains were removed from the cranial cavity and preserved in $10 \%$ formol solutions for 4 weeks. Thereafter brains were dissected along the midsagittal line considering it as an anatomical landmark. With the help of brain knife, the brains were carefully sectioned in the midsagittal plane passing from the body of $\mathrm{CC}$, the hemispheric fissure, the septum pellucidum, cavity of third ventricle and cerebral aqueduct [Figure 1].

The diameters measured were: (i) length of $C C$ $(A B)$ : straight distance from anterior most point to posterior most point of CC, (ii) Width of body of $C C$ at mid point(WMB): Width of CC was measured at the midpoint, which was taken at the center of the $C C$ length, (iii) Maximum width of genu (AE): straight length of genu at the level of anterior most point of CC, (iv) Maximum width of splenium (BD): taken as shown in fig.2, with starting point at posterior most point of CC.

For study purposes, CC was divided into seven segments as proposed in Witelson's topology [7]. According to this straight-line-based topology, CC consists of seven segments named from the anterior to posterior, as rostrum, genu, rostral body, anterior midbody, posterior midbody, isthmus and splenium [12]. In our study out of these seven segments, two were taken into account as fibres passing through these segments interconnect important functional cortical areas of two hemispheres: genu (the anterior third of $A B$ ) contains fibers connecting prefrontal cortices and the posterior third, which is divided into the posterior fifth or splenium $(A B / 5)$ contains occipital visual fibers

Fig. 1: Midsagittal view of corpus callosum (CC) in a cadaveric brain.

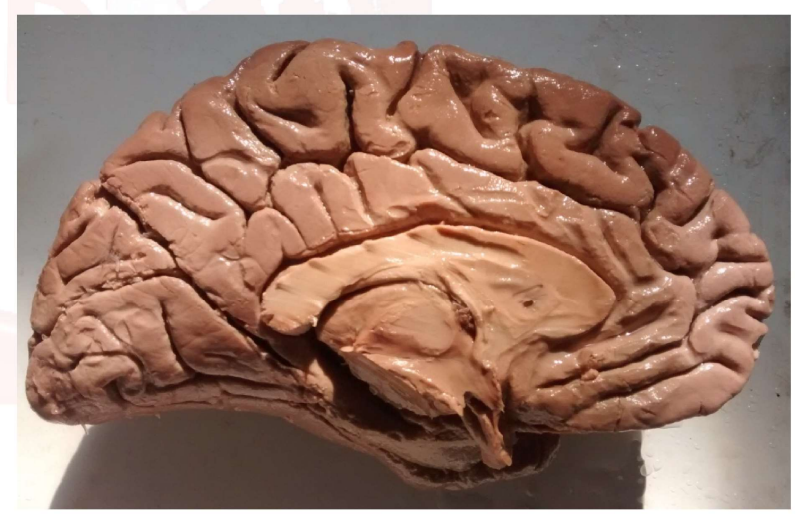

Fig. 2: Showing various morphometric features of CC measured on midsagittal sections of brain.

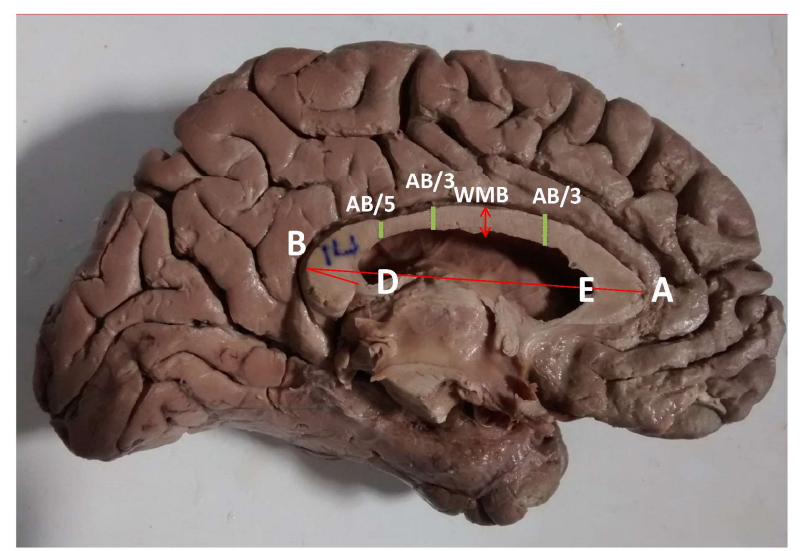

Length of $C C$ ( $A B)$, Width of body of $C C$ at mid point (WBM), maximum width of genu ( $A E)$, Maximum width of splenium (BD)

All the measurements were taken using digital vernier calipers (Mitutoyo, Japan) with least count of $0.01 \mathrm{~mm}$. The measurements were 
repeated three times and the mean was taken as final for further analysis. Results were expressed as mean \pm SD .

Data were analyzed using the Microsoft Excel software for windows 10. A comparison of the mean values between sides and genders was performed using the t-test. $P$ value $<0.05$ was considered statistically significant.

\section{RESULTS}

The values of the various CC parameters were measured individually in each specimen and the data were expressed as mean \pm standard deviation. Statistical analysis of the different CC parameters was done to compare sexual dimorphism using unpaired student' $t$ ' test. The comparison of the mean values of various CC parameters between the two sex and the corresponding $p$ values are tabulated in Table 1. Mean values of two parameters ( $A B$ and $A E$ ) were greater in male than in female. However, 2 parameters (WMB and $B D$ ) had greater value in female than male. Only two parameters $(A B$ and $B D$ ) showed statistically significant ( $p$ value $<0.05$ ) gender differences.

Table 1: The comparison of the mean values of various CC parameters between the two sexes (all the measurements were taken in centimeters).

\begin{tabular}{|c|c|c|c|c|c|c|c|}
\hline \multirow{2}{*}{ Parameter } & \multicolumn{3}{|c|}{ Male } & \multicolumn{3}{|c|}{ Female } & \multirow{2}{*}{$P$ Value } \\
\hline & Mean & Range & $S . D$ & Mean & Range & $S . D$ & \\
\hline$A B$ (longitudinal length of $C C$ ) & 7.06 & $6.10-8.12$ & 0.524 & 6.44 & $5.0-7.5$ & 0.583 & 0.001 \\
\hline $\begin{array}{l}\text { WMB (Width of body of CC at } \\
\text { mid point) }\end{array}$ & 0.43 & $0.38-0.52$ & 0.08 & 0.52 & 0.43-0.62 & 0.12 & 1.643 \\
\hline AE (Maximum width of genu) & 1.31 & $1.23-1.46$ & 0.22 & 1.27 & $1.18-1.32$ & 0.23 & 1.812 \\
\hline $\begin{array}{l}\text { BD (Maximum width of } \\
\text { splenium) }\end{array}$ & 1.18 & 1.18-1.35 & 0.17 & 1.43 & $1.43-1.47$ & 0.15 & 0.003 \\
\hline
\end{tabular}

\section{DISCUSSION}

Morphology of CC and its relation to sex have been studied by many researchers but still remains a matter of debate. Most of the literatures available on sexual dimorphism of CC, have been carried out on MRI scans and relatively few studies are based on formalin-fixed cadaveric brain specimens.

Review of literatures showed that sexual dimorphism has been reported in different parts of CC but there is no consistent parameter that is constant in all studies [13]. Witelson [7] studied CC in detail and concluded that the absolute area of total CC and its various parts such as genu and anterior mid-body were greater in male than in female. On the other hand, isthmus was significantly larger in females. Gupta et al [13] studied the morphology of CC both on preserved brain specimens and MRI scans. They found most of the CC parameters to be similar in both sexes in both the autopsy and the MRI group. The only CC parameters which showed sexual dimorphism were (a) larger CC length in males in the MRI group, (b) the distance between the splenium and superior colliculus was more in males in preserved brains and (c) The distance between the genu and the fornix was more in older males than older females. According to them this significantly larger CC length in males as compared to females in the MRI group is possibly related to larger brain size in males. Suganthy et al [11] and Elster et al [14] also reported longer $\mathrm{CC}$ in males than in females.

Takeda et al [15] reported no sexual difference in the measurements of CC in Japanese subjects.

In the present study two CC parameters were found to be greater in male than in female but two parameters (WMB and $B D$ ) showed reverse trend. However, only two parameters $(A B$ and $B D$ ) showed presence of statistically significant sexual dimorphism.

The splenium has received more attention than any other part of CC in almost all studies on sexual dimorphism. Some studies have reported greater splenial width and area in females $[16,17]$.

Bishop and Wahlstein [5] carried out 19 independent studies of human CC and concluded that there is insufficient evidence to support the presence of sexual dimorphism in the splenium, although overall size of the brain differs in the two sexes.

Luders et al [8] found difference between the splenial size of male and female, however they suggested that effect of individual variations in callosal size was large enough to out range any effect of splenial size differences. In some studies males tended to have larger splenial area although the difference never reached statistical significance.

Witelson [7] also did not report any sex related differences in splenial areas, either in absolute 
size or size proportional to brain weight.

In the present study, the length of splenium (AB/

5 ) was found to be higher in male while and its maximum width (BD) was higher in female. In both cases the difference was statistically significant. This was not in agreement with most of the literature $[10,11,15]$.

Several studies have found significant sex differences in the length, shape and area of the CC of males and females; with females having relatively larger splenium [18, 19]. Sexual dimorphism in CC might be due to greater bi hemispherical representation of cognitive functions in females. This might not simply be due to sex related differences in brain size and may reflect difference in connectivity necessitated by differences in brain size [7].

From clinical standpoint of view, it is often argued that gender differences in human brain morphology may have an impact on cognitive gender differences and may be related to the observed sex differences in age of onset, prevalence, and symptomatology seen in nearly all neuropsychiatric disorders of childhood. Various methods such as cadaveric studies and magnetic resonance imaging (MRI) of brain have been used to study the morphology and anatomical dimensions of the CC.

Recent studies using new techniques revealed morphological sex differences in human CC. These structural changes could be the basis of gender related changes in certain cognitive functions of the brain. Whether and to what extent, these morphological differences are associated with behavioural and cognitive differences between men and women remains unclear.

$\mathrm{CC}$ being the major structural connection between the hemispheres is likely to be affected by physiological as well as pathological changes in the cortical and sub-cortical regions of the brain. The precise anatomical knowledge regarding the morphology of CC as well as the gender related changes of the structure in a certain ethnic population will provide baseline data for the diagnosis and assessment of progression of a disease affecting it.

\section{Conflicts of Interests: None}

\section{REFERENCES}

[1]. Aboitiz F, Scheibel AB, Fisher RS, Zaidel E. Fiber composition of the human corpus callosum. Brain Res. 1992;598:143-53.

[2]. Kulkarni NV. Clinical Anatomy (A Problem Solving Approach). $2^{\text {nd }}$ ed. Jaypee Brothers Medical Publishers. New Delhi. 2011. P 563.

[3]. Williams PL, Bannister LH, Berry MM, Collins P, Dyson M, Dussek JE. Gray's Anatomy : In The Anatomical Basis of Medicine and Surgery. $38 \mathrm{Ed}$. Churchill Livingstone, 2000.

[4]. Sinnathamby CS. Last's Anatomy Regional and Applied. 10 Ed. Edinburgh: Churchill Livingstone, 1999.

[5]. Bishop KM, Wahlsten D. Sex differences in the human corpus callosum: myth or reality? Neuroscience Biobehavioural Review 1997; : 581-601

[6]. Sullivan EV, Rosenbloom MJ, Desmond JE, Pfefferbaun A. Sex differences in corpus callosum size: relationship to age and intracranial size. Neurobiol Aging 2001; 22: 603-11.

[7]. Witelson SF. Hand and sex differences in the isthmus and genu of the human corpus callosum. A postmortem morphological study. Brain 1989; 112: 799-835.

[8]. Luders E, Rex DE, Narr KL et al. Relationships between sulcal asymmetries and corpus callosum size: Gender and handedness effects. Cereb Cortex, 2003; 13: $1084-93$.

[9]. Ilayperuma I, Nanayakkara G, Palahepitiya N. Gross anatomical study on the gender differences in the corpus callosum. Galle Medical Journal. 2009;14(1):22-5.

[10]. Banka S, Jit I. Sexual dimorphism in the size of the corpus callosum. J Anat Soc India 1996; 45: 77-85.

[11]. Suganthy J, Raghuram L, Antonisamy B, Vettivel S, Madhavi C, Koshi R. Gender-and age-related differences in the morphology of the corpus callosum. Clin Anat 2003; 16: 396-403.

[12]. Machado AM. Corpus callosum morphology and ventricular size in chromosome 22q11.2 deletion syndrome. Brain Res. 2007;1131:197-210.

[13]. Gupta T, Singh B, Kapoor K, et al. Normative data of corpus callosal morphology in a north-west Indian population-an autopsy and MRI study. J Nepal Med Assoc 2009;48(173):46-51.

[14]. Elster AD, Dipersio DA, Moody DM. Sexual dimorphism of the human corpus callosum studied by magnetic resonance imaging: fact, fallacy and statistical confidence. Brain Dev 1990;12:321-5.

[15]. Takeda S, Hirashima Y, Ikeda H, Yamamoto H, Sugino $M$, Endo S. Determination of indices of the corpus callosum associated with normal aging in Japanese individuals. Neuroradiol 2003;45:513-8.

[16]. de Lacoste-Utam Singh C, Holloway RL. Sexual dimorphism in the human corpus callosum. Science 1982;216:1431-2.

[17]. Going JJ, Dixson A. Morphometry of the adult human corpus callosum: lack of sexual dimorphism. J Anat 1990;171:163-7. 
[18]. Allen LS, Richey MF, Chai YM, Gorski RA. Sex differences in the corpus callosum of the living human being. J Neurosci 1991;11:933-42.

[19]. Holloway RL, Anderson PJ, Defendini R, Harper C. Sexual dimorphism of the human corpus callosum from three independent samples: Relative size of the corpus callosum. Am J Phys Anthropol 1993;92:481-98.

How to cite this article:

Apurba Patra, Arun Sharma, Vishal Malhotra. SEXUAL DIMORPHISM IN SPLENIAL MORPHOLOGY: A CADAVERIC STUDY. Int J Anat Res 2019;7(2.1):6331-6335. DOI: 10.16965/ijar.2018.423 